\title{
Warm Spells and Climate Risk to Human Health in the Mexico City Metropolitan Area
}

\author{
NURIA VARGAS \\ Posgrado en Geografía, Universidad Nacional Autónoma de México, Mexico City, Mexico \\ VÍCTOR MAGAÑA \\ Instituto de Geografía, Universidad Nacional Autónoma de México, Mexico City, Mexico
}

(Manuscript received 18 July 2019, in final form 11 March 2020)

\begin{abstract}
During the second half of the twentieth century, rapid demographic growth and urban expansion led to the development of the Mexico City metropolitan area (MCMA) urban heat island (UHI). The thermal gradient between rural and urban regions is used to define the UHI in the transition zone along the $26^{\circ} \mathrm{C}$ isotherm of mean maximum temperature. As the MCMA expands, more natural vegetation is replaced with urbanization, and the spatial extent of the $26^{\circ} \mathrm{C}$ isotherm grows. The loss of natural vegetation, in a densely populated region of Mexico, leads to the formation of a canopy-layer UHI. The intensification of the MCMA UHI results in an increase in the frequency of daily maximum temperatures above $30^{\circ} \mathrm{C}$ (above $26^{\circ} \mathrm{C}$ on a weekly average), a threshold value that constitutes a natural hazard. Warm-spell occurrences are related to an increase in the number of acute diarrhea diseases (ADD), mainly in zones of the MCMA where the socioeconomic and environmental conditions are low (e.g., insufficient access to potable water). Vulnerable people are mostly located in new settlements along the periphery of the MCMA, where large numbers of hospital discharges due to ADD are reported. The combined effect of more frequent warm spells and increasing vulnerability results in higher levels of risk of suffering this type of health problem, mainly during the warmest part of the year. This analysis may serve to develop UHI mitigation strategies and early warning systems to manage high levels of ADD risk during warm spells.
\end{abstract}

\section{Introduction}

Climate-related disasters appear to be more frequent in recent decades due to climate change (IPCC 2012). Heat waves are more frequent and intense, contributing to heat mortality in both developed and developing countries (Organisation for Economic Co-operation and Development 2010). However, the idea of more frequent climate impacts on society only as a direct consequence of a positive trend in extreme (warmer) weather conditions frequently follows a naturalistic paradigm (O'Keefe et al. 1976). The vulnerability context in which weather extremes occur has also become an important part of the analysis of climatic risk (Cardona et al. 2012) and a key element to explain the impacts of adverse climate conditions.

One of the best examples on climatic hazards and vulnerability, leading to high levels of risk that affect

\footnotetext{
Corresponding author: Víctor Magaña, victormr@unam.mx
}

urban societies, are megacities (Wolf 2014; Mayrhuber et al. 2018). The well-known urban heat island (UHI) effect, related to increased mean temperatures, may also result in more intense and frequent heat waves (e.g., Zhang et al. 2018). Nevertheless, cities around the world continue their expansion, modifying their climate and increasing people's vulnerability and generating higher climate risk levels (e.g., De Sherbinin et al. 2007; Baker 2012). Estimating changes in the levels of risk is an important problem in the climate change agenda (IPCC 2012). However, there is no universally accepted methodology to evaluate vulnerability to climate change. Various approaches to project the potential impacts of climate change have been developed, but only a few are validated by actually comparing risk and impacts in space and time for recent decades (e.g., Neri and Magaña 2016).

The UHI appears as natural vegetation and surface water bodies are replaced with urban infrastructure (Oke et al. 2017). During the second half of the twentieth century, various cities rapidly grew with a significant loss 
of vegetation and a reduction in the associated ecosystem services, such as those of climate regulation (World Bank 2009). An analysis of climate change impacts in urban environments requires considering how the UHI develops and how such urbanization may result in more exposure and vulnerability. It is highly probable that more climate-related disasters in megacities occur due to increased exposure and vulnerability in regions where frequent extreme weather and climatic conditions occur.

Natural hazards are generally characterized and quantified in terms of measured data. For instance, heat waves in megacities have been described in terms of maximum temperature using station or satellite weather data (e.g., Jedlovec et al. 2017). However, human vulnerability to extreme weather conditions is more difficult to quantify. Assessing climate vulnerability begins by posing three basic questions (Neri and Magaña 2016): 1) Who is vulnerable [object of study: people of the Mexico City metropolitan area (MCMA)]? 2) To what are they vulnerable (natural hazard: warm spells)? 3) Why are they vulnerable (vulnerability factors: socioeconomic conditions, access to health and basic services, environmental conditions)? Various analyses suggest that vulnerability to warm spells depends on socioeconomic factors such as age, low standards of living, limited access to health services, or diminished ecosystemic services (Rey et al. 2009; Tan 2008). In recent years, more studies focus in determining the factors that make people vulnerable to heat waves in cities (e.g., He et al. 2019). In particular, the mortality related to heat waves has been analyzed for Latin American cities because of the need to develop prevention strategies in the health sector (Bell et al. 2008).

Heat waves may have negative effects on the health of vulnerable people (Kovats and Hajat 2008), but until recently most studies have mainly focused on heat strokes and the combined effect of heat waves and air pollution (Scortichini et al. 2018). However, warm-spell conditions on vulnerable people may also result in other types of health problems, such as acute diarrhea diseases (ADD) (e.g., Checkley et al. 2000). In recent decades, ADD rates in Mexico have diminished, but they still remain an important health problem, particularly among children under 5 years old (Riojas Rodríguez et al. 2006).

The development of the UHI in the MCMA has been documented by a number of authors (e.g., Jáuregui 2000; Cui and de Foy 2012). During the twentieth century, the temperature of the MCMA increased between $2^{\circ}$ and $3^{\circ} \mathrm{C}$ (Jáuregui 2009). Heat waves, defined as three or more consecutive days with maximum temperature above $30^{\circ} \mathrm{C}$, are more frequent. Warm spells, related to weekly averaged maximum temperatures above $26^{\circ} \mathrm{C}$, are considered a natural hazard in Mexico City. In recent years in the
MCMA UHI, there are on the order of 10-20 warm spells per decade, whereas a century ago there used to be fewer than 3 per decade (Jáuregui 2009). These events occur mainly between March and May under low relative humidity conditions ( $\sim 20 \%$ ). To adapt to climate change, the change in climate risk and the factors that induce such changes should be documented.

Managing more intense warm spells in the MCMA UHI is becoming a challenge for public health agencies, particularly in the new poor developments on the periphery of the metropolitan area. Public policies and prevention measures aimed at reducing climatic risk require a better understanding of the ways in which enhanced heat waves affect vulnerable people. Therefore, the main objective of the present study is to document the climatic risks on human health generated by more intense warm spells in the UHI of the MCMA, mainly during the spring season.

\section{Data and method}

The method to relate urban development to health problems is based on the construction of risk estimates that explain how a natural hazard (e.g., warm spells) in a vulnerable context results in climate risks and climaterelated impacts (e.g., Neri and Magaña 2016). This approach involves characterizing natural hazards based on observed data and quantifying vulnerability by means of indicators of the physical, environmental, and socioeconomic context. Warm spells are documented using maximum temperature daily recorded by the meteorological surface weather stations in the MCMA and surrounding region (Servicio Meteorológico Nacional 2018) for the 1950-2015 period. The number of stations in the domain of interest has varied in time from around 50 at the beginning of the 1950s to almost 200 in the late 1980s, and around 150 in recent years (Fig. 1).

Gridded daily fields of maximum temperature were constructed for the 1 January 1950 to 31 December 2015 period using a successive corrections scheme (Cressman 1959; Magaña et al. 2013). For this purpose, first-guess daily fields of maximum temperature were obtained from the North American Regional Reanalysis (NARR) project (Mesinger et al. 2006), with a spatial resolution of $32 \mathrm{~km} \times 32 \mathrm{~km}$, that were linearly interpolated to $4 \mathrm{~km}$ by $4 \mathrm{~km}$ grids. The higher-spatial-resolution NARR estimates of maximum temperature were further modified using a standard moist adiabatic lapse rate $\left(6.5^{\circ} \mathrm{C} \mathrm{km}^{-1}\right)$ to correct for the effect of temperature change with height. The objectively analyzed maximum temperature fields were validated by comparing time series of station data with values at nearby grid points. The objectively analyzed maximum temperature fields correlate well with station data nearby $(>0.8)$ (not shown). 


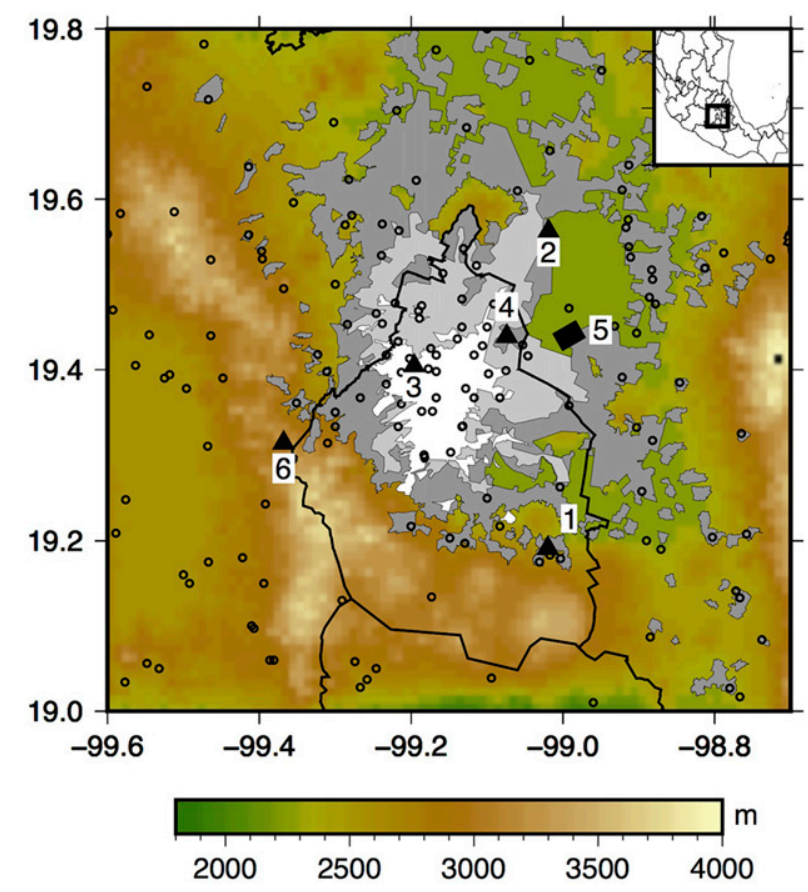

FIG. 1. Urban extension of the MCMA for the years 1950 (white), 1980 (light gray), and 2005 (dark gray). The circles correspond to surface weather stations in the domain. The numbers correspond to the locations of surface weather stations: 1) Milpa Alta, 2) Ecatepec, 3) Tacubaya, 4) Airport, 5) Texcoco, and 6) La Marquesa. The color shades correspond to the height $(\mathrm{m})$ of the topography.

Defining the UHI in the MCMA requires determining the temperature contrasts between the rural and urban regions. The MCMA is located in the lower part of the valley of Mexico, surrounded by mountains (Fig. 1). The temperature decreases with height, resulting in a natural large thermal gradient between the lower and higher parts. But the MCMA UHI has formed mainly in relation to land-use changes, from natural vegetation to urban infrastructure. Therefore, the UHI may be defined as a canopy-layer UHI (Oke et al. 2017), where deforestation and urbanization enhance the local warming and the thermal contrasts between urban and rural regions. Most of the MCMA is in a region where large population density and low vegetation levels coexist. The MCMA may be identified using information on vegetation and population density. Population density data were obtained for the years 2000 and 2010 from the Socioeconomic Data and Applications Center (2018).

The spatial growth of the MCMA approximately coincides with negative changes in the vegetation levels and increases in population density. The level of vegetation in the domain of interest was described using the enhanced vegetation index (EVI), which serves to estimate biomass and monitor vegetation through a decoupling of the canopy background signal and a reduction in atmosphere influences (Huete et al. 2002). EVI ranges between -0.2 and 1. For the MCMA, it was found that values between 0 and 0.2 approximately correspond to highly urbanized zones. When EVI and population density data are combined into a single index, the largest values are encompassed by the political boundary of the MCMA.

Daily maximum temperatures above $30^{\circ} \mathrm{C}$ are considered to be a natural hazard that may affect people's health (Harlan et al. 2006). Weekly reports of ADD cases are provided by the Health Agencies of Mexico [Comisión Federal para la Protección contra Riesgos Sanitarios (COFEPRIS) 2018]. Anomalously large weekly maximum temperatures (above $26^{\circ} \mathrm{C}$ ) were defined as warm spells or heat waves over the region (Jáuregui 2009). Information on ADD and warm spells was compared for the 2000 and 2011 period to establish a relationship between climate risk and impact. In the MCMA, the maximum temperatures are seldom above $30^{\circ} \mathrm{C}$, and the effects of heat waves on the population are rarely related to heat stroke (Jáuregui 2009). As empirically determined by health agencies, heat waves appear to be associated with ADD [COFEPRIS 2018; Comisión Nacional del Agua (CONAGUA) 2015] mainly among children under 5 years old, which is considered a highly vulnerable group. However, the assessment of climate vulnerability requires conceptualizing various factors that make people or socioecosystems susceptible of suffering harm under hazardous conditions (United Nations International Strategy for Disaster Reduction 2009). In addition to age, poverty constitutes a vulnerability factor to heat waves, since the possibilities of building an environment of thermal comfort are meager (e.g., air conditioning systems) (e.g., Reid et al. 2009).

The use of socioeconomic indicators, obtained during the official census in Mexico for 2000 and 2010 [Instituto Nacional de Estadística, Geografía e Informática (INEGI) 2018], allows a characterization of the vulnerability of people to heat waves. For instance, their vulnerability may depend on whether they have access to basic medical services (Reyes et al. 1998) or education to know self-risk management strategies (e.g., Cid Ortiz et al. 2012). Overcrowding in neighborhoods, poor water quality for human use and consumption, inadequate disposal of excreta, and bad hygienic conditions of housing and public spaces have also been considered important vulnerability factors that may induce ADD. Socioeconomic data from INEGI (2018) have been used as proxies for the construction of vulnerability indicators on access to potable water, health services, population density, access to domestic services (such as refrigerators), and literacy level. In addition, the natural vegetation level (EVI) in the surroundings has been used and averaged 


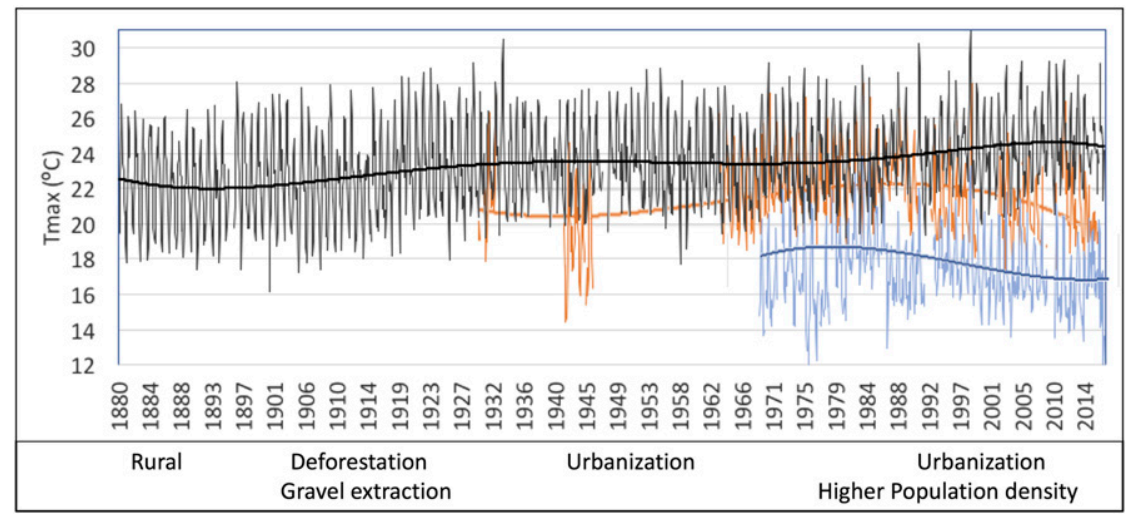

FIG. 2. Time series of mean monthly observed maximum temperature at the Tacubaya station (1878-2016) (thin black line), at the Milpa Alta station (1929-2016) (thin orange line), and at the La Marquesa station (thin blue line). The thick solid lines correspond to a smoothed version (the very low frequency variations) of the observed maximum temperature at each station. Periods of important land use changes in the Tacubaya region are indicated at the bottom.

with the socioeconomic indicators to obtain a normalized vulnerability index to warm spells. After a number of tests and discussion with experts, it was decided that the level of access to potable water has a larger importance than the other factors, and therefore it has been given a larger (5 times) weight in the vulnerability index.

A preliminary climate risk estimate is obtained from the product of the natural hazard (the 90th percentile of daily maximum temperature) times the corresponding vulnerability. Risk estimates should approximately explain the temporal and spatial characteristics of ADD cases at the municipal level. If the risk model is adequate, the vulnerability factors are considered to be correct, and risk management strategies should focus on them. In the case of the UHI climatic risk, some actions have also been proposed to reduce the magnitude of the natural hazards, for instance, by means of reforestation (e.g., Wang and Akbari 2016).

The Federal Commission for Health Risk Management (COFEPRIS 2018) reports cases of hospital discharges of people who have been directly or indirectly affected by diarrhea disease. Weekly reports on children between 0 and 5 and 5 and 14 years old affected by ADD are used a measure of the warm spells' impact. This information is compared with climate risk estimates for the MCMA.

\section{Results}

\section{a. The evolution of the MCMA UHI}

The maximum temperatures in the MCMA have significantly increased during the twentieth and twenty-first centuries. In the western part of the city, for instance, around the Tacubaya station (Fig. 1), there has been an increase in the mean annual maximum temperature from around $22^{\circ} \mathrm{C}$ at the end of the nineteenth century to approximately $25^{\circ} \mathrm{C}$ in recent years (Fig. 2). The incremental transitions in maximum temperature occur by stages, as land-use changes take place, from natural vegetation to dense urbanization. In this process, at the end of the nineteenth century and the beginning of the twentieth century, the maximum temperature changed from $22^{\circ}$ to $23^{\circ} \mathrm{C}$, as deforestation and extraction of materials in the region took place. Between 1920 and 1965, the maximum temperature remained relatively stable until rapid urbanization occurred in the 1970s, resulting in a new temperature regime between $24^{\circ}$ and $25^{\circ} \mathrm{C}$. The maximum temperature has remained relatively stable since then. This warming process in the western part of the MCMA shows that the climate forcing related to land-use changes (e.g., deforestation-urbanization) has had important effects on the local climate (Oke et al. 2017). A similar pattern of loss of natural vegetation and increases in the mean maximum temperature has been observed over most of the MCMA. In rural regions nearby Tacubaya, as in La Marquesa or Milpa Alta (Fig. 1), the increase in maximum temperature in recent decades has been relatively small $\left[<1^{\circ} \mathrm{C}(50 \mathrm{yr})^{-1}\right]$ given that these regions tend to maintain their natural vegetation. This contrast implies that the urbanization and loss of natural vegetation have created the MCMA UHI.

Maximum temperatures in the MCMA are usually higher between March and May (boreal spring), prior to the rainy season. The orographic gradients in the domain lead to lower surface temperatures in the southern and western parts of the region, over the mountain range. The extent of the urban area rapidly grew in recent decades, resulting in increments of the surface temperature. Spatially, the UHI approximately coincides with 

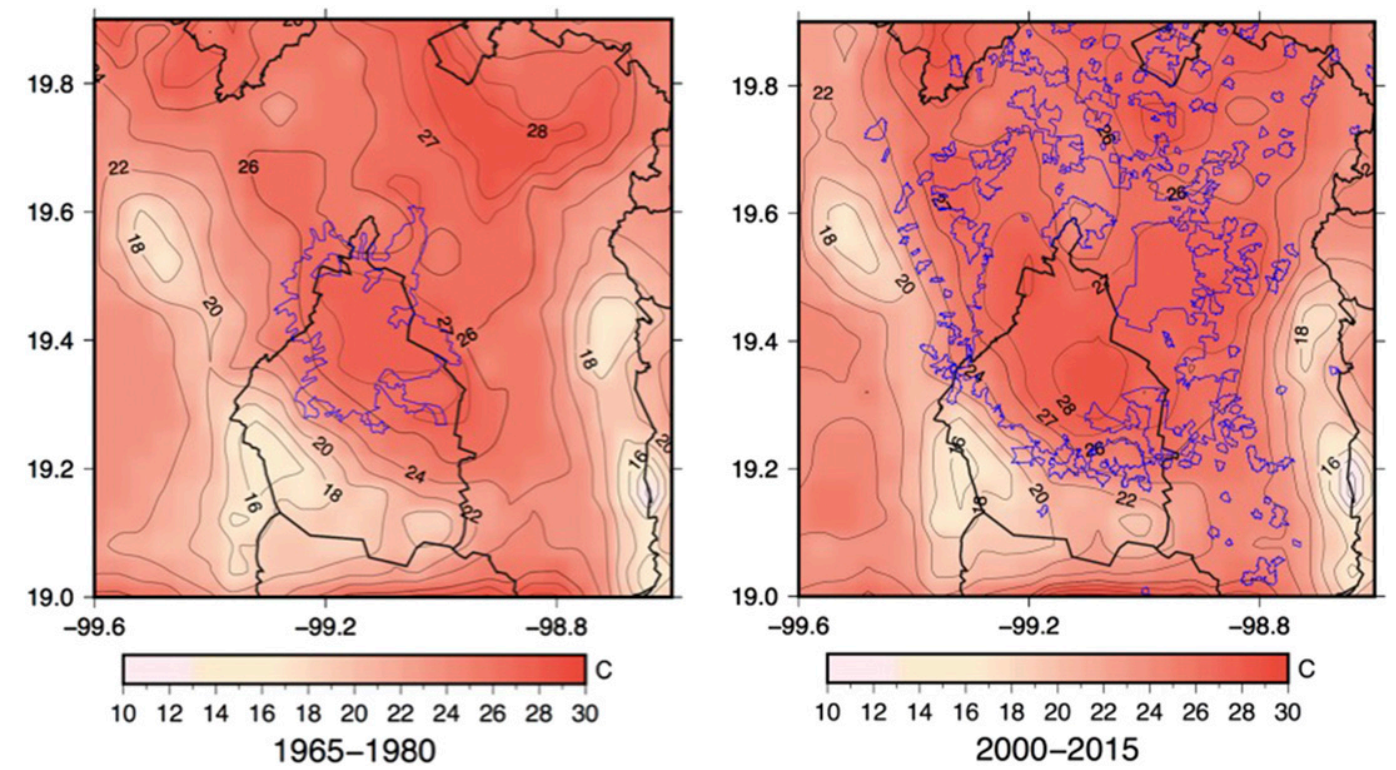

FIG. 3. Mean maximum temperatures $\left({ }^{\circ} \mathrm{C}\right.$ ) for March-May in the MCMA for the (left) 1965-80 and (right) 2000-15 periods. The thin blue line in the background denotes the extent of the urban area in 1980 and 2010.

the $26^{\circ} \mathrm{C}$ isotherm, which expands as the urban area enlarges (Fig. 3). For the 1965-80 period, most of the urbanization was located in the central part of the Mexico valley, where an average spring maximum temperature was around $27^{\circ} \mathrm{C}$ (Fig. 3, left panel). As the city grew, the UHI expanded and the $26^{\circ} \mathrm{C}$ isotherm covered a much larger area. In recent decades (2000-15), the urban area enlarged mainly to the northeastern and northwestern parts of the Mexico City valley and the UHI pattern is similar to the urban expansion of the MCMA (Fig. 3, right panel). In the eastern side of the MCMA, mean maximum temperatures have reached more than $28^{\circ} \mathrm{C}$ in the urban area, that is, a warming rate of more than $1^{\circ} \mathrm{C}$ in 30 years.

In the central and northern parts of the MCMA, daily and even monthly maximum temperatures may be larger than $30^{\circ} \mathrm{C}$, particularly in recent years, which turns into a natural hazard and leads to a climate risk for vulnerable people. The number of episodes of $30^{\circ} \mathrm{C}$ or more has increased in various parts of the MCMA. In the Tacubaya station, the number of heat waves changed from 2 or 3 per decade at the beginning of the twentieth century to more than 20 per decade at the end of the twentieth century (Jáuregui 2009).

The magnitude of temperature increases depends on the characteristics of the urbanization process (Oke et al. 2017). The level of conservation of the natural vegetation is an important element to modulate maximum temperature (Bolund and Hunhammar 1999). When changes in maximum temperature in two different landscapes of the MCMA are compared, the role of the natural vegetation may be estimated. For instance, in Ecatepec, a densely populated region in the northeastern part of the MCMA, vegetation is sparse, and concrete, iron, and glass dominate the landscape. There, the increase in mean maximum temperature due to the UHI effect is almost $3.2^{\circ} \mathrm{C}$ in 30 years (Fig. 4, left panel). On the other hand, in Milpa Alta, a rural, less populated area in the southern part of the MCMA, natural vegetation and agricultural lands have been relatively conserved. There, a weaker increase $\left(1^{\circ} \mathrm{C}\right)$ in mean maximum temperature in recent decades is observed (Fig. 4, right panel). The natural vegetation modulates mean temperature at the local and even regional level, providing an important ecosystem service of climate regulation. However, in Milpa Alta and Ecatepec, as in most of the MCMA, there has been an increase of around $5 \%$ in the frequency of events of $30^{\circ} \mathrm{C}$, suggesting that warmer temperatures, as those related to warm spells, are related to the UHI intensification.

\section{b. Loss of natural vegetation and maximum temperatures}

The urban expansion in the MCMA in recent decades results in natural vegetation loss at a rapid pace. Developers prefer increasing the areas for buildings and houses over conserving, at least partially, natural vegetation. By means of the EVI, it is possible to distinguish the extension of urbanization and regions where vegetation has changed during the twentieth-first century. The EVI estimates can be associated with wooded areas (Hussein et al. 2017), which, for urban climate purposes, are important regions where evapotranspiration may mitigate UHI intensity (Ballinas and Barradas 2016). In the 

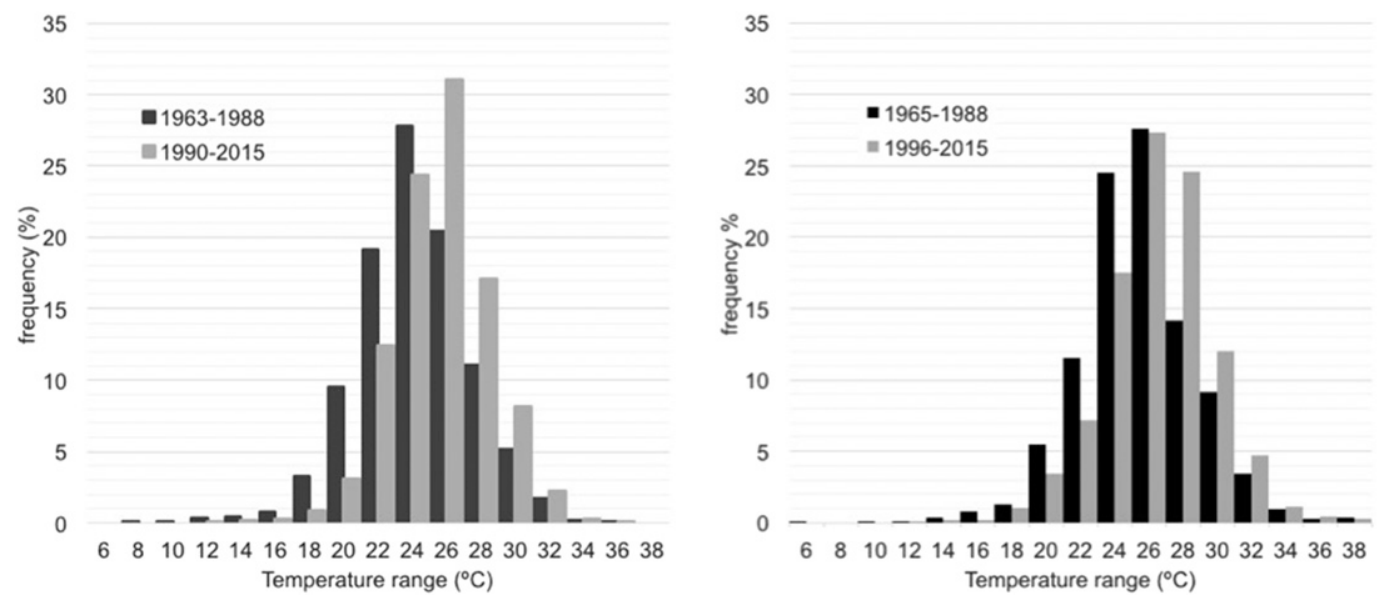

FIG. 4. Histograms of daily maximum temperature for (left) Ecatepec, between 1963 and 1988 (black bar) and between 1990 and 2015 (gray bar), and (right) Milpa Alta, for 1965-88 (black bar) and 1996-2015 (gray bar).

MCMA, EVI values of less than 0.1 nearly correspond to an absence of trees in highly urbanized areas (Fig. 5). The use of land-use and land-cover data over the MCMA (Buchhorn et al. 2019) indicates that most of natural vegetation has been changed for urban areas (not shown). It is empirically determined that for the MCMA case, the EVI contour of around 0.2 approximately corresponds to urban areas. In areas of larger mean September EVI values, natural vegetation appears to provide a climate-regulation service. When the EVI is compared for two periods, such as 2000-04 and 2011-15, the urban and less vegetated regions show an expansion, mainly to the northeastern and northwestern parts of the MCMA. In the eastern part of the domain, south of Nabor Carrillo Lake (Fig. 1), the sparse vegetation coincides with one of the most densely populated and low-income regions in the country. In the southern foothills of the domain, the forest area is gradually being occupied by new human settlements that are diminishing the extent of the natural vegetation, despite the existing conservation policies. Urban growth in the MCMA results in vegetation losses and warming since the energy balance is modified (Jáuregui 2009). In the recently urbanized areas, such land-use change has resulted in temperature increases between $1^{\circ}$ and $2^{\circ} \mathrm{C}$ in 20 years (Jáuregui 2009). The largest warming in urbanized areas corresponds to the areas of asphalt, urban infrastructure, or bare soil.

EVI and population densities have changed from the 2000-04 period to the 2011-15 period, mainly on the periphery of the MCMA, toward the northeast and northwest (Fig. 6, left panel). In the central part of the MCMA, population density has slightly decreased. However, the vegetation loss continues over most of the region, inducing changes in the UHI. Maximum temperature changes between the two periods are large in the eastern part of the MCMA (Fig. 6, right panel), where loss of vegetation and population density have changed significantly.

An additional factor that modulates maximum temperature in a large portion of the MCMA is heat advection. This term has been neglected in previous calculations of the drivers of the MCMA UHI (e.g., Ballinas and Barradas 2017). The effect of the afternoon mountain breeze in the southern and western part of the Mexico valley reduces the warming of the southern central parts of the UHI in the afternoon hours. Between 1400 and $1500 \mathrm{LT}$, the cool mountain-valley breeze blows to southern part of the MCMA (Fig. 7), advecting air of less than $25^{\circ} \mathrm{C}$ from the foothills toward the urban area. The cooling effect of this process may be as large as $3^{\circ} \mathrm{Ch}^{-1}$. The gradual loss of so-called natural vegetation conservation areas in the southern mountains may result in a weakening of the cool air advection process and an enhancement and expansion of the UHI. Therefore, the growth of the MCMA in recent decades has resulted in an enlarged and more intense UHI, with mean spring maximum temperatures close to $29^{\circ} \mathrm{C}$ in the centraleastern part of the urban area, that is, more than $2^{\circ} \mathrm{C}$ larger than three decades ago.

\section{c. Extreme maximum temperature as a natural hazard}

Increases in maximum temperature become a natural hazard when they represent a threat to human health and comfort. Warm spells are usually defined with respect to the local climatology of a region. Various definitions have been posed for warm spells, but in general, they are described as periods of unusually hot and dry or hot and humid weather that have a subtle onset and cessation and a duration of at least two to three days, and they 

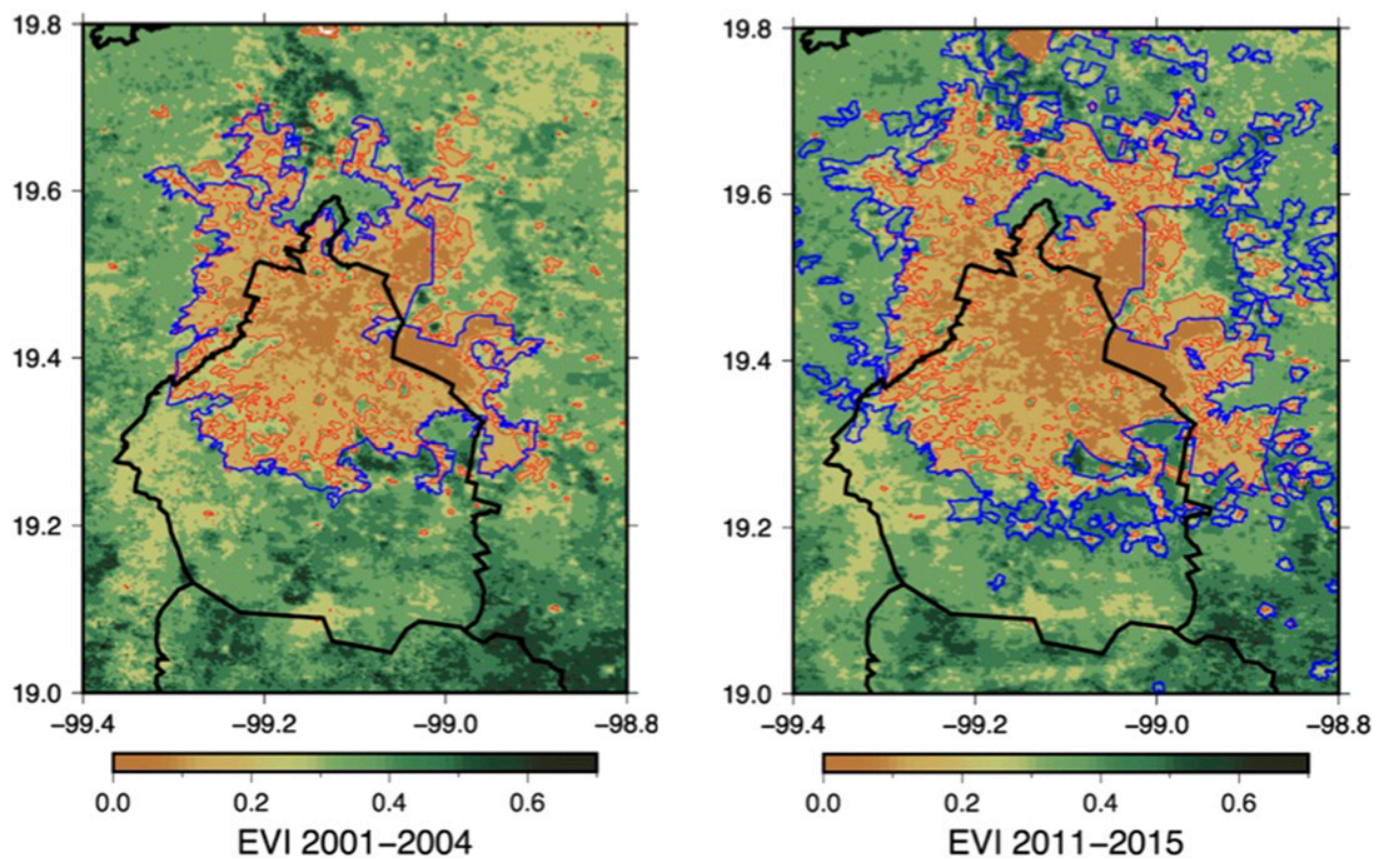

FIG. 5. Mean EVI for September in the MCMA for the: (left) 2000-04 and (right) 2011-15 periods. The thin blue line in the left and right panels corresponds to the limits of urbanization for 2000 and 2010, respectively. The red line denotes the logarithm of the population density (thousands of people per square kilometer).

usually have a discernible impact on human and natural systems (McGregor 2015). Maximum temperatures in the MCMA mostly occur during March, April and May, some of the driest months of the year, and are seldom above $30^{\circ} \mathrm{C}$. The 90 th percentile of maximum temperature shows the area potentially affected with extreme temperatures. During the $1965-80$ period, a $10 \%$ chance of extreme maximum temperatures is usually above $28^{\circ} \mathrm{C}$, over the
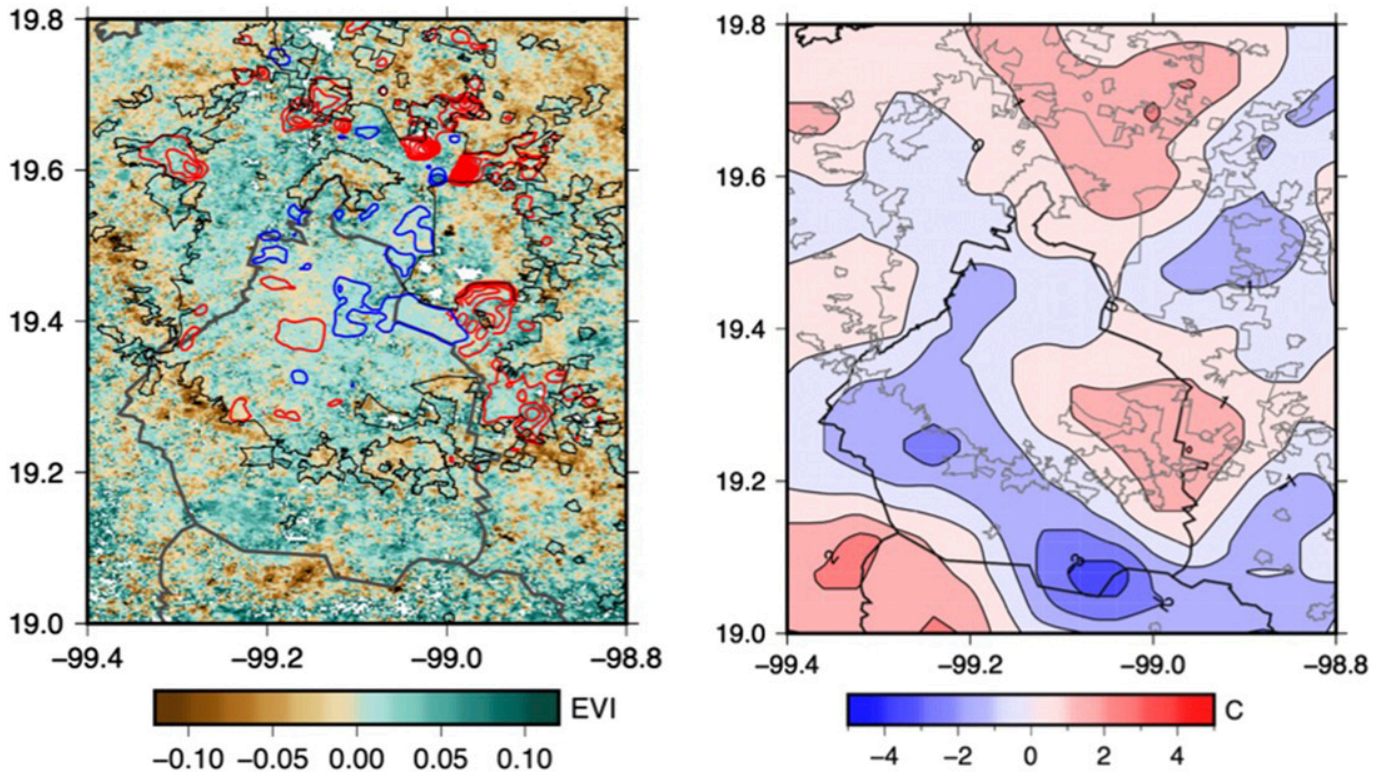

FIG. 6. (left) Change in mean September EVI between the average conditions of the 2000-04 period and the 2011-15 period. The population density (persons per square kilometer) changes between 2000 and 2015 are denoted with isolines, with red or blue lines indicating an increase or decrease in population density, respectively. (right) Change in mean March-May maximum temperature $\left({ }^{\circ} \mathrm{C}\right)$ between the 2000-04 and 2011-15 periods. 


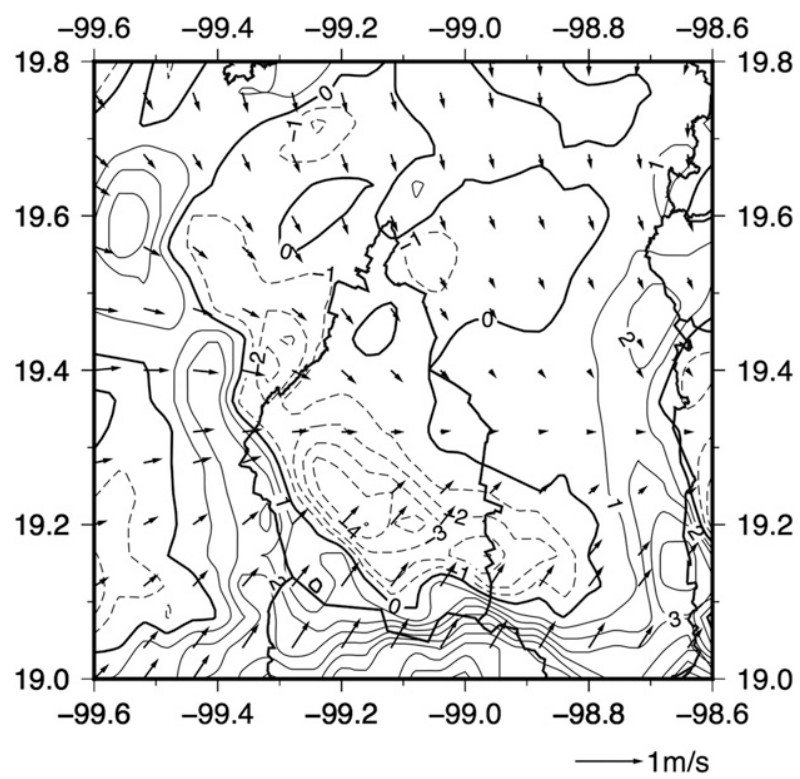

FIG. 7. Long term means of the 2100 UTC (1500 LT) April surface wind (vectors) and heat advection $\left({ }^{\circ} \mathrm{Ch}^{-1}\right.$; contours). Cooling in the southern part of the MCMA by heat advection is represented by dashed lines.

urbanized area of central Mexico City (Fig. 8, left panel). However, for the 2000-15 period, this area extended to northwest and northeast, as a result of urbanization (densely populated areas with little or no natural vegetation). The 90th percentile of daily maximum temperature is above $29^{\circ}$ and $30^{\circ} \mathrm{C}$ over a large part of the UHI (Fig. 8, right panel). In central eastern Mexico
City, daily maximum temperatures over $34^{\circ}$ and $35^{\circ} \mathrm{C}$ for two consecutive days have already been recorded in recent years. In areas that maintain part of their natural vegetation, changes in the 90th percentile of daily maximum temperatures are weaker than in regions where vegetation was lost, as in the newly urbanized regions. During El Niño years, chances of maximum temperatures above $33^{\circ} \mathrm{C}$ increase, as in the spring of 1998, when maximum temperatures for several consecutive days occurred in April (Magaña 1999). The number of days with maximum temperature above $30^{\circ} \mathrm{C}$ has increased by more than $10 \%$ in recent decades, which implies an increase in the frequency of warm spells (Jáuregui 2009).

\section{d. The impacts of heat waves in the MCMA: Acute diarrhea diseases}

In several regions of Mexico, the impacts of heat waves have been associated with heat stroke or other cardiovascular diseases. In Mexicali, in northern Mexico, maximum temperatures above $40^{\circ} \mathrm{C}$ are frequent (e.g., Jaramillo Ramírez et al. 2011) and result in large mortality rates (Díaz Caravantes et al. 2014). However, in the MCMA the maximum temperatures rarely reach values that may threaten human life in such manner. In recent years however, diarrheal disease cases in the northeastern part of the MCMA tend to occur more frequently during the warmest months of the year: March, April, or May (Fig. 9). This may be related to human consumption of food rotted by hot weather or to pollution associated with stronger winds, dust, and bacteria dispersion. In the MCMA, more than

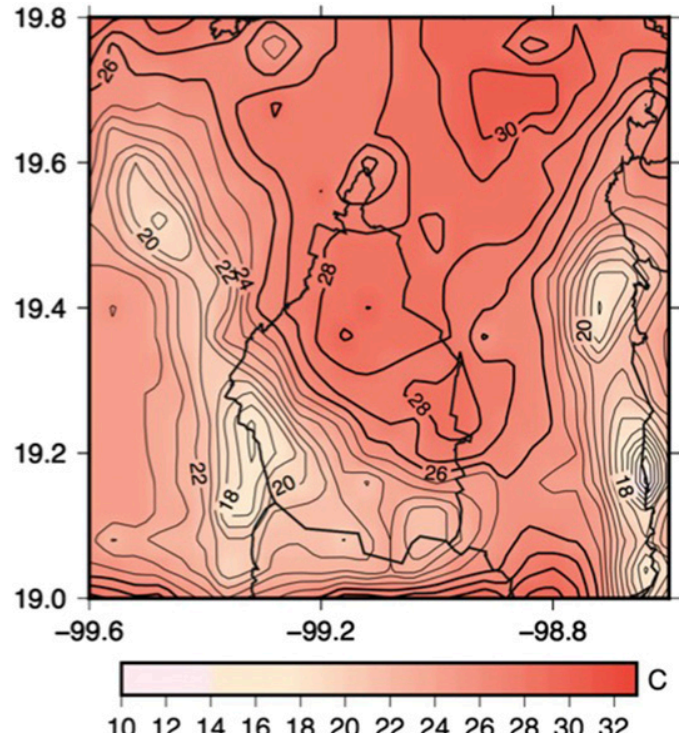

101214161820222426283032

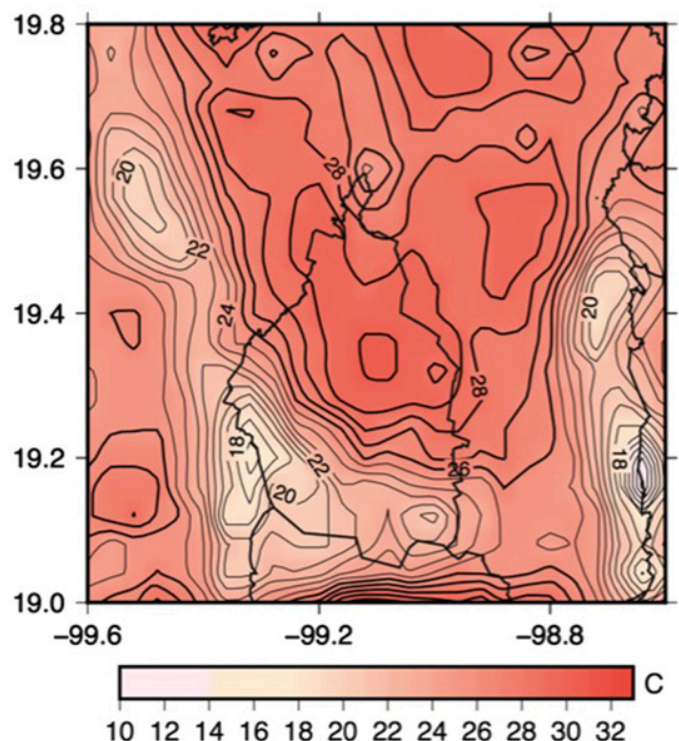

FIG. 8. Ninetieth percentile of daily maximum temperature, in the MCMA for the (left) 1965-80 and (right) 2000-15 periods. 


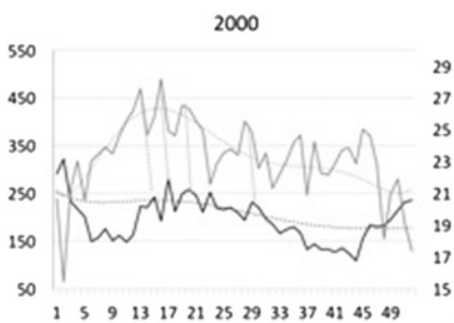

2001

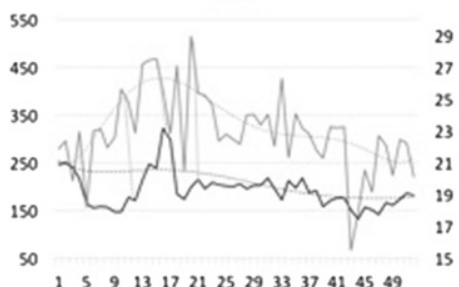

2002
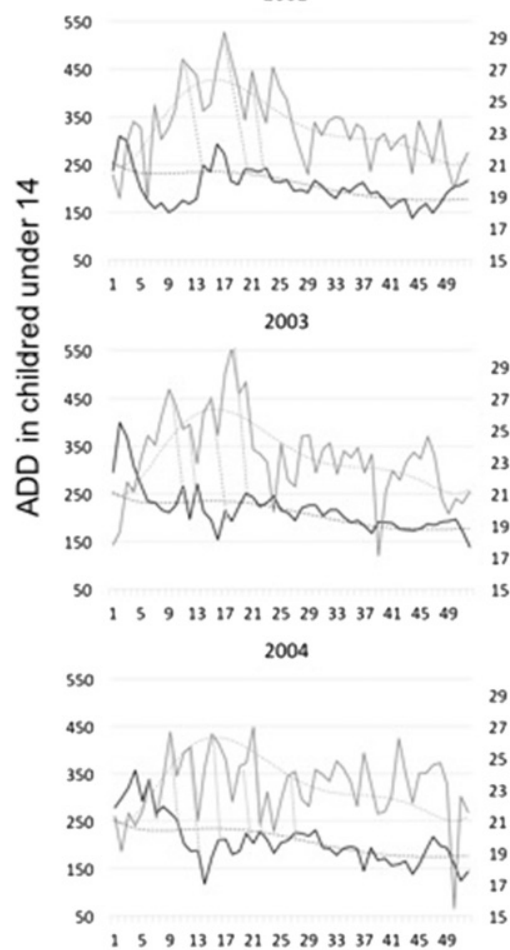

2005

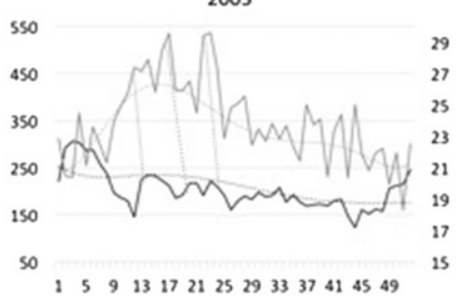

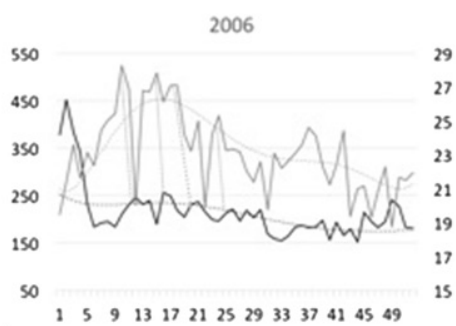

2007

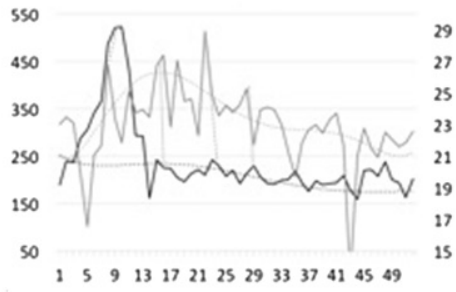

2008

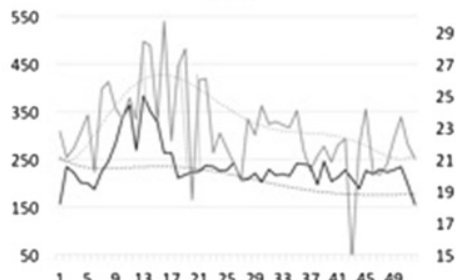

2009

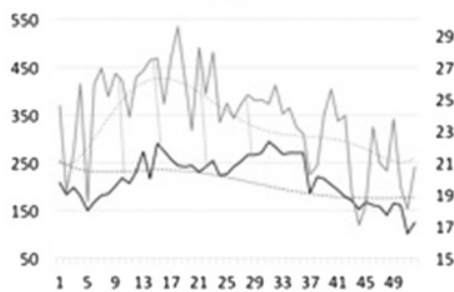

2010

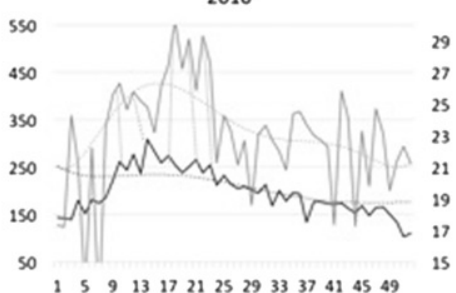

2011

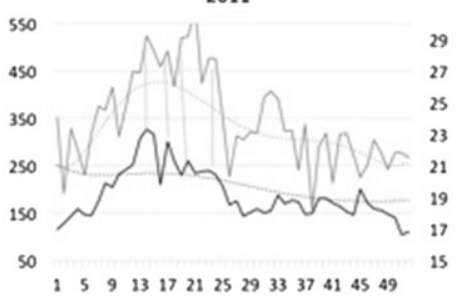

weeks

FIG. 9. Weekly number of hospital discharges for acute diarrhea diseases (ADD) for children between 0 and 14 years old in the MCMA (black line) and averaged weekly maximum temperatures over the MCMA (gray line). The smooth solid lines correspond to their weekly climatology. Dashed tilted lines show the correspondence between an increase in maximum temperatures and increases in the number of ADD. 
$90 \%$ of the population has access to water inside their houses. However, some people living in the eastern part of the city, or in municipalities near the central region, lack basic public services such as potable drinking water (INEGI 2018). The limited access to this service, particularly during the dry warm season, contributes to the lack of hygienic measures and the proliferation of ADD, mainly among children, particularly during heat-wave periods, when interruptions in the distribution of water are more frequent.

To determine the relationship between heat and ADD episodes, weekly maximum temperatures averaged over the MCMA and diarrhea reports among children between 0 and 14 years old are examined for the 2000-11 period (Fig. 9). The spatial average of weekly maximum temperature is used, considering that heat waves affect the entire domain. In most years of this period, weekly maximum temperatures above the average (climatology) appear to lead to increases in the number of ADD reports one or two weeks later, mostly during the spring months. The time difference is related to the process of acquiring the disease, going to the hospital, and being discharged. Data show that warm spells and ADD hospital discharge reports are usually larger between March and May. The Mexican Ministry of Health considers there is an expected number of cases every week, but the situation becomes anomalous when the number of ADD reports is above such expected value. In general, the intensity of the warm spell is not proportional to the increase in the number of ADD repots. However, warmer-thannormal weekly maximum temperatures are generally followed by an increase in the number of ADD cases in children.

The previous analysis shows that warm spells in the MCMA may affect people's health, but the magnitude of the impact does not only depend on the maximum temperature anomaly. The socioeconomic and environmental context is important to determine the regions of the MCMA, where warm spells may affect the most.

\section{e. Vulnerability and risk under warm spells}

A larger number of people exposed to warm spells increases the magnitude of the impacts. The MCMA population increased from around 5 million people in the 1950s, to around 20 million in 2010 (INEGI 2018). A large percentage of the population in Mexico has obesity and cardiovascular problems (DiBonaventura et al. 2018). These factors can make the population vulnerable to episodes of higher-than-average temperatures-for instance, above $30^{\circ} \mathrm{C}$ - that occur during warm spells in the highly urbanized zones of the MCMA. Some proposals suggest that the vulnerability of people of the MCMA to extreme heat depends on six factors (among others): (i) access to basic domestic services (potable water), (ii) access to health services, (iii) population density (overcrowding in houses), (iv) degree of illiteracy (to be informed on climate risks), (v) degree of vegetation cover, and (vi) refrigerator availability. All of these indicators are dynamic (vary in time) and may be described in terms of official data. For instance, the largest increase in people's density takes place in new settlements, in the northeastern part of the MCMA. In the present vulnerability analysis, it was found that people are more vulnerable to heat waves and experience ADD when access to potable water is insufficient.

The normalized indicators are constructed using official census information from recent years: 2000 and 2010 (INEGI 2018), obtained with data at the municipal level and higher spatial resolution. The hazard data, corresponding to the 90th percentile of maximum temperature is combined with the vulnerability index to obtain ADD risk indices for 2000 and 2010. During 2000, the most vulnerable population was located mostly in the eastern part of the MCMA, that is, in the State of Mexico (Fig. 10, left panel). In 2010, the most vulnerable people were located in the new settlements, on the periphery of the domain of study, mainly in the northeastern part of the MCMA (Fig. 10, right panel), suggesting that new settlements delay in receiving basic urban services. Some of the most vulnerable places correspond to irregular settlements, with limited access to public health services and potable water. Their environment is usually degraded with little natural vegetation and high pollution levels (Makhelouf 2009). Low vulnerability in the old central part of the MCMA suggests that its population has reached a higher socioeconomic level and adequate urban services throughout the years.

The 90th percentile of maximum temperature is larger toward the eastern, northeastern, and northwestern zones of the MCMA. Climatic risk of ADD to warm spells, among children between 0 and 14 years old, has increased in recent years (Fig. 11). The areas of high levels of risk approximately correspond to the distribution of the zones with a large number of hospital discharge reports related to ADD among children, that is, in the northern and eastern parts of the urban area (Fig. 12). The largest number of ADD reports (at the municipal level) are also observed in the northeastern and northwestern parts of the MCMA, in approximate agreement with the high climatic risk index. There are differences in the exact location of the maximum number of ADD reports and risk estimates, since some people in the State of Mexico municipalities frequently move to the nearest hospitals in Mexico City 

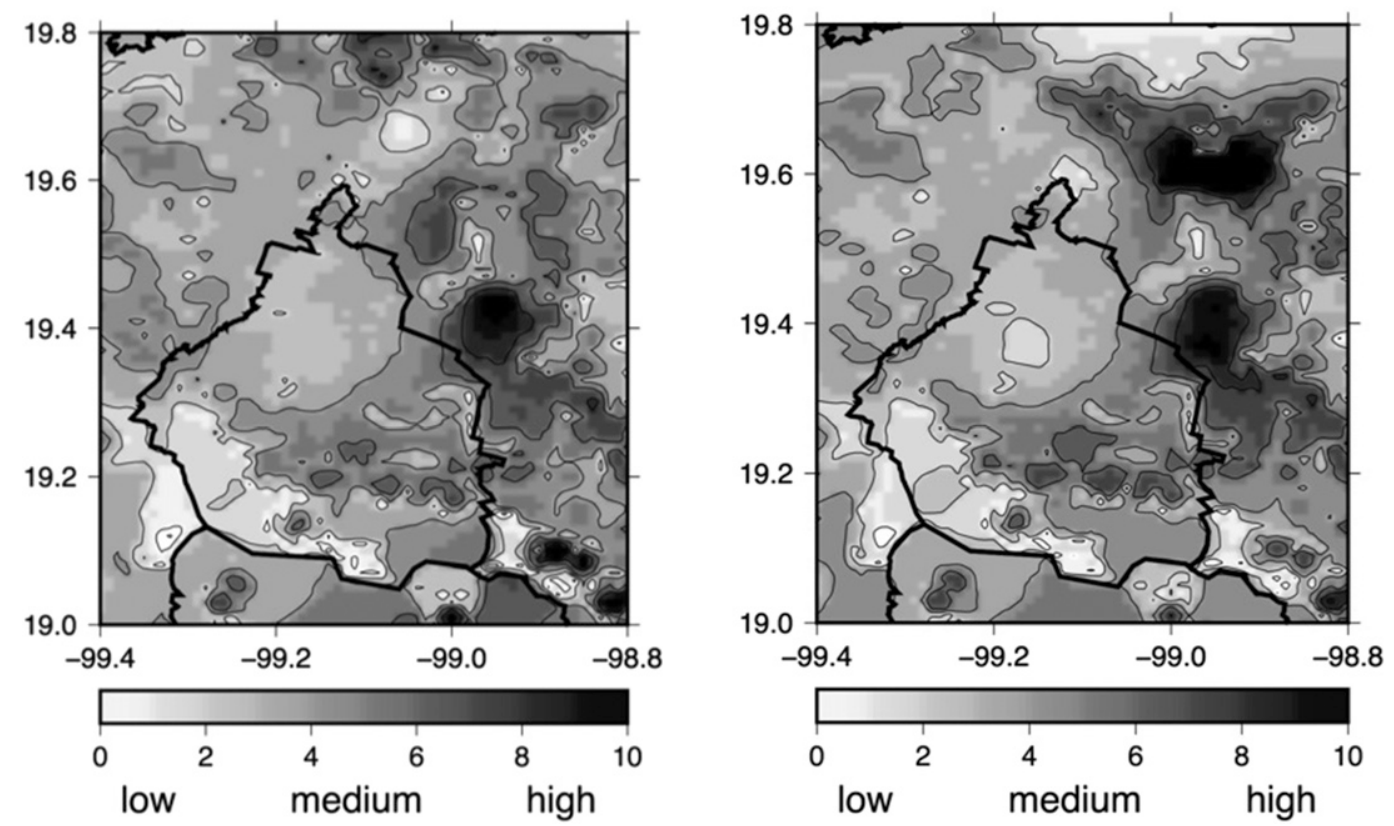

FIG. 10. Vulnerability index to extreme maximum temperature for heat waves for (left) 2000 and (b) 2010 in the MCMA. The scale bar is a reference to low and high values only.

area to be treated. Given that the data correspond to reports on the patients treated in hospitals, there could be a bias in the precise location of the report.

Therefore, it is high temperature but also the condition of vulnerability, that is, risk, that better explains the impacts of the temporal and spatial distribution of ADD. The limitation on the information about cases of diarrhea (place where the person acquired the disease) caused by extreme heat reduces the skill of the risk model to better define the location of the impacts. This is obviously part of the uncertainty of any risk model. Nevertheless, the importance of a risk approach to propose adequate adaptation measures to warm spells in the MCMA is now available to define a prevention strategy in the health sector.

\section{Summary and conclusions}

The urban expansion of the MCMA has resulted in an UHI that tends to increase the magnitude and frequency of warm spells. The environmental and socioeconomic conditions of this urban area create vulnerabilities to anomalously high maximum temperature. During the warm season, warm spells may result in increased risk of ADD outbreaks in the central eastern and northeastern parts of the MCMA, characterized as the most vulnerable zones. We conclude that an urban development that reduces or eliminates natural vegetation results in warmer temperatures and a horizontal growth and intensification of the UHI. Most of the time it is irregular settlements on the periphery of the city, with low socioeconomic conditions and limited access to potable water, that provoke environmental degradation and make people more vulnerable to warm spells. This is common in the urban expansion of the MCMA, which exacerbates social vulnerability by increasing exposure, the loss of ecosystem services, and poor socioeconomic conditions. Children are particularly vulnerable to heat waves.

According to our study,

(i) the expansion of the MCMA has resulted in an increase of maximum temperature (mean and extremes),

(ii) the loss of natural vegetation in the urbanization process generates changes in temperature that, in combination with heat-wave activity, results in a natural hazard for people's health,

(iii) vulnerability to heat waves and risk of ADD in the eastern and northern parts of the MCMA are mainly related to an enhanced UHI and socioeconomic conditions, and

(iv) this analysis may serve to develop a heat-health early warning system for the MCMA.

Climate risk management is aimed at reducing, for instance, the negative impacts of warm spells. The estimates of climate risk based on probabilities of higher temperatures above a critical threshold should serve to design structural measures to manage risk, 


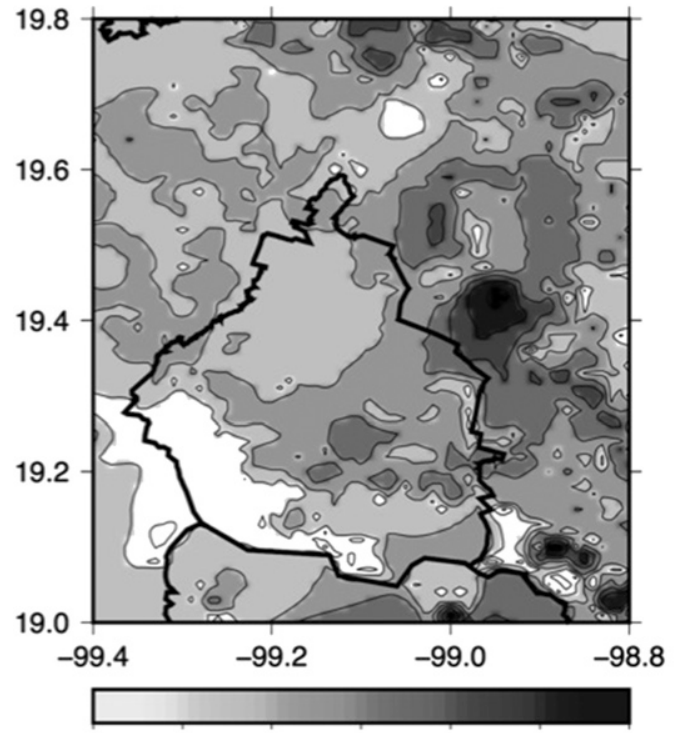

low medium high

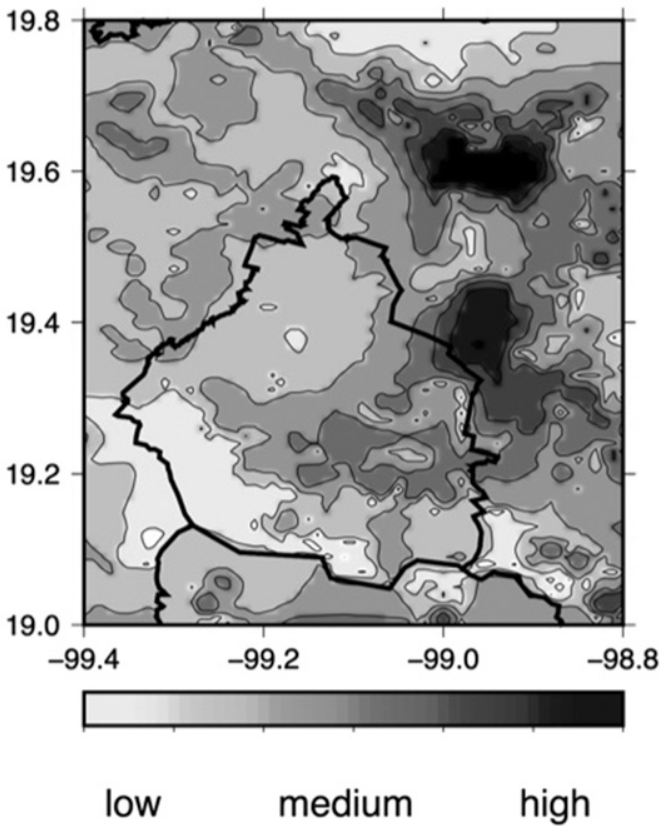

FIG. 11. Risk of ADD under warm spells in the MCMA for the (left) 2000-04 and (right) 2010-14 periods.

including mitigation of the UHI. On the other hand, when risk is calculated based on observed conditions for a particular day or week or on weather forecasts, a response to critical risk may be based on an early warning system. Our results indicate that an early warning to warm spells in the MCMA may be issued a week in advance, particularly for the most vulnerable regions. Improved weather forecasts and climate risk information are important elements to face the increase in the frequency and magnitude of heat waves. Although the warm episodes occur over most of the MCMA, adaptation strategies should be implemented in the regions under high risk, as suggested by the World Health Organization (2015), and it could be implemented based on a risk approach, once an adequate communication strategy is developed.
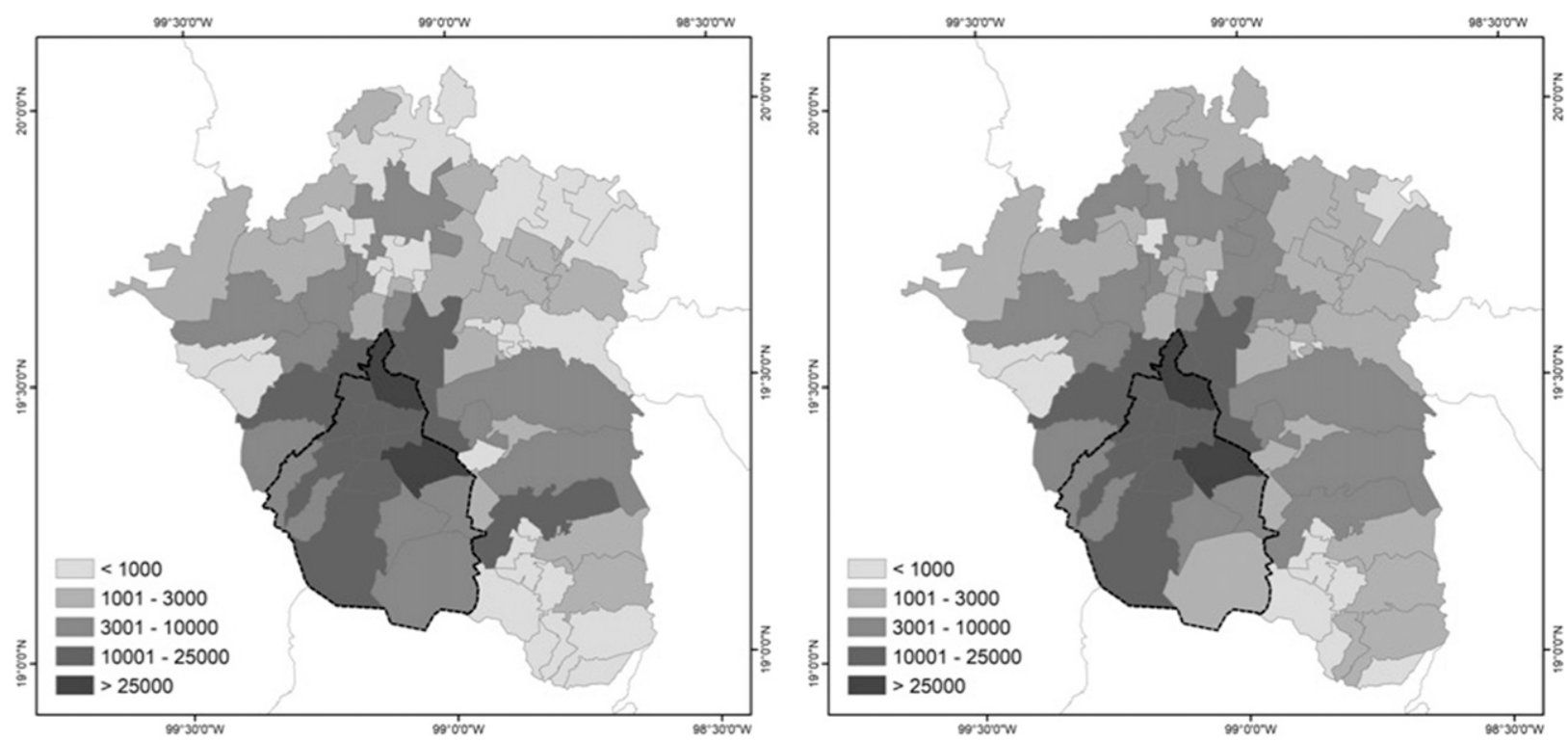

FIG. 12. Number of reports of hospital discharges after ADD for children between 0 and 14 years old at the municipal-level MCMA for March-June of (left) 2000-04 and (right) 2007-11 (data source: COFEPRIS). 
Climate risk management also requires mitigation of warm spells by reducing the magnitude of the UHI, for instance, by means of urban reforestation in the eastern part of the MCMA. It also requires adaptation, which involves addressing the vulnerability factors, such as information to people on the conditions that favor ADD. Not all the socioeconomic conditions that result in vulnerability may be modified to reduce risk, but its quantification is necessary to determine when high levels of risk are reached.

Most medium-sized cities in Mexico follow an urban growth pattern similar to the one observed in the MCMA, in which the construction of infrastructure (buildings, roads, etc.) is more important than maintaining natural ecosystem services (conservation of trees and natural vegetation in general). An attribution exercise of the UHI may serve to determine where urban reforestation or other mitigation strategies may be implemented (e.g., recovery of rivers). Such studies would be of benefit to a society interested in climate risk management.

It is necessary that, in the near future, better information on the direct impacts of heat on people of the MCMA, such as heat stroke, be prepared. Adaptation to the UHI or climate change requires redefining the strategies for human settlements, mainly on the periphery of the urban area, by improving their access to better environmental and economic living conditions. The interest of the Mexican government in climate change should also address the problem of the UHI by establishing urban reforestation programs or improved public health services in vulnerable regions. Climate risk scenarios in megacities may serve to better plan land use in medium-sized cities experiencing rapid demographic growth.

Acknowledgments. We thank Gustavo Vazquez, who kindly helped with the preparation of meteorological data. Tania Pérez and Moises Lopez helped in processing satellite and socioeconomic data provided by LANOTUNAM. We are indebted to Narda Vazquez for her kind assistance in preparing data from COFEPRIS. We thank three anonymous reviewers for valuable comments to the original version of the paper. Discussions with Rodolfo Acuña on the relationships between climate and health were extremely valuable. We also thank Guadalupe de la Luz Gonzalez for providing data on health at the municipal level. This project was financially supported with a grant from UNAM PAPIIT-112717. Nuria Vargas was financially supported with a CONACYT scholarship (371862). This paper also benefitted from several comments in the UNAM-Seminar on Socioenvironmental Risks (SURSA). The support of Conacyt-FORDECYT/12SE/2018/11/29-05 is also appreciated.

\section{REFERENCES}

Baker, J. L., 2012: Climate Change, Disaster Risk and the Urban Poor: Cities Building Resilience for a Changing World. World Bank Publications, 316 pp.

Ballinas, M., and V. Barradas, 2016: The urban tree as a tool to mitigate the urban heat island in Mexico City: A simple phenomenological model. J. Environ. Qual., 45, 157-166, https:// doi.org/10.2134/JEQ2015.01.0056.

Bell, M. L., M. S. O’Neill, N. Ranjit, V. H. Borja-Aburto, L. A. Cifuentes, and N. C. Gouveia, 2008: Vulnerability to heatrelated mortality in Latin America: A case-crossover study in São Paulo, Brazil, Santiago, Chile and Mexico City, Mexico. Int. J. Epidemiol., 37, 796-804, https://doi.org/10.1093/ije/dyn094.

Bolund, P., and S. Hunhammar, 1999: Ecosystem services in urban areas. Ecol. Econ., 29, 293-301, https://doi.org/10.1016/S09218009(99)00013-0.

Buchhorn, M., B. Smets, L. Bertels, M. Lesiv, N.-E. Tsendbazar, M. Herold, and S. Fritz, 2019: Copernicus Global Land Service: Land Cover 100m: Epoch 2015: Globe. Copernicus Land Monitoring Service, accessed 11 February 2020, https:// doi.org/10.5281/zenodo.3243509.

Cardona, O. D., and Coauthors, 2012: Determinants of risk: Exposure and vulnerability. Managing the Risks of Extreme Events and Disasters to Advance Climate Change Adaptation, C. B. Field et al., Eds., Cambridge University Press, 65-108.

Checkley, W., L. Epstein, and R. Gilman, 2000: Effects of El Niño and ambient temperature on hospital admissions for diarrhoeal diseases in Peruvian children. Lancet, 355, 442-450, https://doi.org/10.1016/S0140-6736(00)82010-3.

Cid Ortiz, G., C. Castro Correa, and V. Rugiero De Souza, 2012: Percepción del riesgo en relación con capacidades de autoprotección y autogestión, como elementos relevantes en la reducción de la vulnerabilidad en la ciudad de La Serena (Perception of risk in relation to self-protection and selfmanagement capacities, as relevant elements in reducing vulnerability in the city of La Serena). Rev. INVI, 27, 105-142, https://doi.org/10.4067/S0718-83582012000200004.

COFEPRIS, 2018: Bases de datos sobre egresos hospitalarios (Databases of hospital discharges), 17 January 2019. https:// www.gob.mx/salud/acciones-y-programas/historico-boletinepidemiologico.

CONAGUA, 2015: Agua, salud y medio ambiente (Water, health, and environment). In Estadísticas del Agua en México: edición 2015 (Statistics of water in Mexico: 2015 edition), Gobierno de México Secretaría de Medio Ambiente y Recursos Naturales Comisión Nacional del Agua Rep., 179-181, accessed 12 May 2018, http://www.conagua.gob.mx/CONAGUA07/Publicaciones/ Publicaciones/EAM2015.pdf.

Cui, Y. Y., and B. de Foy, 2012: Seasonal variations of the urban heat island at the surface and the near-surface and reductions due to urban vegetation in Mexico City. J. Appl. Meteor. Climatol., 51, 855-868, https://doi.org/10.1175/JAMC-D-11-0104.1.

Cressman, G. P., 1959: An operational objective analysis system. Mon. Wea. Rev., 87, 367-374, https://doi.org/10.1175/ 1520-0493(1959)087<0367:AOOAS > 2.0.CO;2.

De Sherbinin, A., A. Schiller and A. Pulsipher, 2007: The vulnerability of global cities to climate hazards. Environ. Urbanization, 19, 39-64, https://doi.org/10.1177/0956247807076725.

Díaz Caravantes, R. E., A. L. Castro Luque, and P. Aranda Gallegos, 2014: Mortalidad por calor natural excesivo en el noroeste de México: Condicionantes sociales asociados a esta causa de muerte (Mortality from excessive natural heat in 
northwestern Mexico: Social determinants associated with this cause of death). Frontera Norte, 26, 155-177.

DiBonaventura M., H. Meincke, A. Le Lay, J. Fournier, E. Bakker and A. Ehrenreich, 2018: Obesity in Mexico: Prevalence, comorbidities, associations with patient outcomes, and treatment experiences. Diabetes, Metab. Syndr. Obes.: Targets Ther., 11, 1-10, https://doi.org/10.2147/dmso.s129247.

Harlan, S., A. Brazel, L. Prashad, L. Stefanov, and L. Larsen, 2006: Neighborhood microclimates and vulnerability to heat stress. Soc. Sci. Med., 63, 2847-2863, https://doi.org/10.1016/ J.SOCSCIMED.2006.07.030.

He, C., L. Ma, L. Zhou, D. K. Hai, Y. Zhang, C. M. Wei, and B. Chen, 2019: Exploring the mechanisms of heat wave vulnerability at the urban scale based on the application of big data and artificial societies. Environ. Int., 127, 573-583, https:// doi.org/10.1016/j.envint.2019.01.057.

Huete, A., K. Didan, T. Miura, E. P. Rodriguez, X. Gao, and L. G. Ferreira, 2002: Overview of the radiometric and biophysical performance of the MODIS vegetation indices. Remote Sens. Environ., 83, 195-213, https://doi.org/10.1016/S0034-4257(02) 00096-2.

Hussein, S., F. Kóvacs, and Z. Tobak, 2017: Spatiotemporal assessment of vegetation indices and land cover for Erbil City and its surrounding using MODIS imageries. J. Environ. Geogr., 10, 31-39, https://doi.org/10.1515/JENGEO-2017-0004.

INEGI, 2018: Censos de población y vivienda 2000 y 2010 (Population and housing censuses 2000 and 2010). Accessed 15 March 2019, https://www.inegi.org.mx/programas/ccpv/ 2010/default.html\#Datos_abiertos.

IPCC, 2012: Managing the Risks of Extreme Events and Disasters to Advance Climate Change Adaptation. Cambridge University Press, 582 pp., https://www.ipcc.ch/report/managing-the-risksof-extreme-events-and-disasters-to-advance-climate-changeadaptation/.

Jaramillo Ramírez, H. J., G. López Cota, and M. Rodríguez Lomelí, 2011: Golpe de calor: Un problema de salud pública en Mexicali. Salud Pública de México, 53, 285-286, https:// doi.org/10.1590/s0036-36342011000400001.

Jáuregui, E., 2000: Breve descripción del clima de la Cuenca de México (Brief description of the Mexico Basin climate). El Clima de la Ciudad de México (The Climate of Mexico City), Temas Selectos de Geografía de México, Plaza y Valdés, 31-43.

- 2009: The heat spells of Mexico City. Invest. Geogr., 70, 71-76, https:// pdfs.semanticscholar.org/ad73/9a6c7bac37154d9b99d5fa514cfa06db7c01. pdf?.ga=2.46396709.305979132.1586110582-601156690.1586110582.

Jedlovec, G., D. Crane, and D. Quattrochi, 2017: Urban heat wave hazard and risk assessment. Results Phys., 7, 4294-4295, https://doi.org/10.1016/j.rinp.2017.10.056.

Kovats, R. S., and S. Hajat, 2008: Heat stress and public health: A critical review. Annu. Rev. Public Health, 29, 41-55, https:// doi.org/10.1146/annurev.publhealth.29.020907.090843.

Magaña, V., 1999: Los Impactos de El Niño en México (The Impacts of El Niño in Mexico). UNAM, 229 pp., http://centro.paot.org.mx/ index.php/porinstituciones/otros-organismos/73-varios/745los-impactos-de-el-nino-en-mexico.

__ L. C. López, and G. Vázquez, 2013: El pronóstico de lluvias intensas para La Ciudad de México (Forecasting heavy rain for Mexico City). TIP Rev. Espec. Cienc. Quim.-Biol., 16, 1825, https://doi.org/10.1016/S1405-888X(13)72074-6.

Makhelouf, A., 2009: The effect of green spaces on urban climate and pollution. Iran. J. Environ. Health Sci. Eng., 6, 35-40.

Mayrhuber, E. A. S., and Coauthors, 2018: Vulnerability to heatwaves and implications for public health interventions-A scoping review. Environ. Res., 166, 42-54, https://doi.org/ 10.1016/j.envres.2018.05.021.

McGregor, G. R., 2015: Heatwaves and Health: Guidance on WarningSystem Development. World Meteorological Organization, 96 pp.

Mesinger, F., and Coauthors, 2006: North American Regional Reanalysis. Bull. Amer. Meteor. Soc., 87, 343-360, https:// doi.org/10.1175/BAMS-87-3-343.

Neri, C., and V. Magaña, 2016: Estimation of vulnerability and risk to meteorological drought in Mexico. Wea. Climate Soc., 8, 95110, https://doi.org/10.1175/WCAS-D-15-0005.1.

Oke, T., G. Mills, A. Christen, and J. Voogt, 2017: Urban Climates. Cambridge University Press, 546 pp., https://doi.org/10.1017/ 9781139016476.

O'Keefe, P., K. Westgate, and B. Wisner, 1976: Taking the naturalness out of natural disasters. Nature, 260, 566-567, https:// doi.org/10.1038/260566a0.

Organisation for Economic Co-operation and Development, 2010: Cities and Climate Change. OECD Publishing, 276 pp., https:// doi.org/10.1787/9789264091375-en.

Reid, C. E., M. S. O'Neill, C. J. Gronlund, S. J. Brines, D. G. Brown, A. V. Diez-Roux, and J. Schwartz, 2009: Mapping community determinants of heat vulnerability. Environ. Health Perspect., 117, 1730-1736, https://doi.org/10.1289/ehp.0900683.

Rey, G., A. Fouillet, P. Bessemoulin, P. Frayssinet, A. Dufour, E. Jougla, and D. Hémon, 2009: Heat exposure and socioeconomic vulnerability as synergistic factors in heat-waverelated mortality. Eur. J. Epidemiol., 24, 495-502, https:// doi.org/10.1007/s10654-009-9374-3.

Reyes, H., P. Tomé, G. Gutiérrez, L. Rodríguez, M. Orozco, and H. Guiscafré, 1998: La mortalidad por enfermedad diarreica en México: ¿Problema de acceso o de calidad de atención? (Diarrheal disease mortality in Mexico: A problem of access or of quality of care?) Salud Publica Mex., 40, 316-323, https:// doi.org/10.1590/S0036-36341998000400003.

Riojas Rodríguez, H., M. Hurtado Diìaz, J. Idrovo Velandia, and H. Vaìzquez Grameix, 2006: Estudio diagnóstico sobre los efectos del cambio climático en la salud humana de la población en México: Informe final (Diagnostic study on the effects of climate change on the human health of the population of Mexico: Final report). Instituto Nacional de Ecología Instituto Nacional de Salud Pública, 33 pp., http://www2.inecc.gob.mx/ descargas/cclimatico/e2006h.pdf.

Scortichini, M., M. De Sario, F. K. De'Donato, M. Davoli, P. Michelozzi, and M. Stafoggia, 2018: Short-term effects of heat on mortality and effect modification by air pollution in 25 Italian cities. Int. J. Environ. Res. Public Health, 15, 1771, https://doi.org/10.3390/ijerph15081771.

Socioeconomic Data and Applications Center, 2018: Gridded Population of the World, version 3 (GPWv3): Population density grid, V. 3.00. Center for International Earth Science Information Network, Columbia University, and Centro Internacional de Agricultura Tropical, NASA Socioeconomic Data and Applications Center, accessed 8 April 2019, https:// doi.org/10.7927/H4XK8CG2.

Servicio Meteorológico Nacional, 2018: Mexico National Weather Service Data Base. Government of Mexico, accessed 13 July 2018, https://smn.conagua.gob.mx/es/climatologia/informacionclimatologica/informacion-estadistica-climatologica.

Tan, J., 2008: Commentary: People's vulnerability to heat wave. Int. J. Epidemiol., 37, 318-320, https://doi.org/10.1093/ije/ dyn023.

United Nations International Strategy for Disaster Reduction, 2009: Terminology on disaster risk reduction. United Nations 
Office for Disaster Risk Reduction Doc., 30 pp., https:/ www.unisdr.org/files/7817_UNISDRTerminologyEnglish.pdf.

Wang, Y., and H. Akbari, 2016: The effects of street tree planting on urban heat island mitigation in Montreal. Sustainable Cities Soc., 27, 122-128, https://doi.org/10.1016/ j.scs.2016.04.013.

Wolf, T., 2014: Performance assessment of a heat wave vulnerability index for Greater London, United Kingdom. Wea. Climate Soc., 6, 32-46, https://doi.org/10.1175/WCAS-D-13-00014.1.

World Bank, 2009: Convenient solutions to an inconvenient truth: Ecosystem-based approaches to climate change. World Bank
Publications, 128 pp., http://documents.worldbank.org/curated/ en/745791468150298239/Convenient-solutions-to-an-inconvenienttruth-ecosystem-based-approaches-to-climate-change.

World Health Organization, 2015: Heatwaves and health: Guidance on warning-system development. WMO Publ. 1142, 96 pp., https://www.who.int/globalchange/publications/ WMO_WHO_Heat_Health_Guidance_2015.pdf?ua =1.

Zhang, L., Z. Zhang, T. Ye, M. Zhou, C. Wang, P. Yin, and B. Hou, 2018: Mortality effects of heat waves vary by age and area: A multi-area study in China. Environ. Health, 17, 54, https:// doi.org/10.1186/s12940-018-0398-6. 